\title{
The Effect of Social Media and Peer Group on The SPIRIT Characters Formation of The Students
}

\author{
Arcadius Benawa, Silverius Lake CJM
}

\begin{abstract}
The aim of this research is to find out the perception of the students on the effect of social media and peer-group to the SPIRIT characters formation. To achieve the aim of this research, the method that be used is a quantitative research method where the research data was obtained by distributing questionnaires to the students who were respondents, then the data obtained was processed with SPSS program and analyzed by path analysis. The result of this research indicated that the effect of social media on the SPIRIT Characters formation was not significant, because it was only 15\%, meanwhile the effect of peer group on the SPIRIT character formation was also not significant, because it was only 17.8\%. Therefore, it can be concluded that social media and peer group had no significant effect on the character SPIRIT formation. So, it is very necessary to deepen this research to find out what kind of variables that have a significant effect on the SPIRIT characters formation and why social media and peer groups did not significantly influenced the SPIRIT characters formation..
\end{abstract}

Index Terms: Social media; peer group; SPIRIT characters.

\section{INTRODUCTION}

Education is the best and most effective way and tools to shape the character of the students. According to Ki Hajar Dewantara, education itself is basically character building.[1] It is relevant with the vision of Bina Nusantara University. But it will not have meaning if we do not take advantage of the opportunities as well as possible. It is very important and relevant if there is an evaluation of education held at Bina Nusantara University towards the formation of the SPIRIT characters of the students.

The main objective of this study is to see the extent of the effect of social media and peer groups on the formation of the SPIRIT characters. This is done after one year ago the effect of leadership and organizational culture on the formation of the SPIRIT characters was examined.[2] Therefore it is an urgent question to ask is to what extent do social media and peer groups influence the formation of the SPIRIT characters of the students?

The main problem is what kind of social media conditions that can be used as a challenge for students to build their

\section{Revised Manuscript Received on September 22, 2019}

Arcadius Benawa, Character Building Development Center, Mass Communication Program, Communication Department, Faculty of Economics \& Communication, Bina Nusantara University, Jakarta, Indonesia.

Silverius Lake CJM,Character Building Development Center, Mass Communication Program, Communication Department, Faculty of Economics \& Communication, Bina Nusantara University, Jakarta, Indonesia.
SPIRIT characters. For that the very important and relevant thing in the Character Building learning process is how the students can use social media seriously and critically so that social media is conducive to the formation of the SPIRIT characters. Likewise related to the peer group. The extent to which students peer groups are conducive and effective for the formation of the SPIRIT characters of the students.

The aim of this research is to find out the understanding of the students about the extent to which social media is effective to shape the formation of the SPIRIT characters, and the extent to which the peer group also contributes to the character formation of the SPIRIT effectively and significantly to build..

\section{LiteratURE REVIEW}

According to Andreas K. and Michael H, social media is a set of internet-based applications that are based on ideology and Web 2.0 technology, so social media enable the creation of user-generated content and exchanges.[3] Merriam-Webster explained that social media is a form of electronic communication (for an example a website) so that people can communicate online to share information, ideas, personal messages, etc.[4] According to Obar, social media is a set of technologies which mediated by computers that can help in creating, disseminating information, such as ideas, career interests, as well as various other forms of information through community and virtual networks.[5] Various social media services have sprung up today and each introduces a distinctive service model; however, there are also some general features.

Hajirnis described that more than 60 percent of the children between the ages of 13 up to 17 have at least one profile on their social media, and they spend an average of more than two hours a day on their social media networking sites.[6] Meanwhile, according to Nielsen the users of the internet generally spend more time on social media sites than on all other types of sites. In line with this fact, it is known that the total time spent on social media sites in the US on all PCs and mobile devices has increased significantly, which is more than 99 percent.[7] That is, to be 121 billion minutes on July 2012 compared to the previous figure of 66 billion minutes in July 2011.

Based on some understandings of the social media above can be concluded that social media is electronic or non-electronic tools that used to make communication among humans, whether it is among individuals with individuals, or individuals with organizations or companies. 
According to sociology, peer groups are social groups that are characterized by similar interests (homophiles), as well as similarities in age, background, or social status that are on the same level.[8] These peer group members tend to influence the beliefs and behavior of group members. Meanwhile Laurence Steinberg stated that peer groups tend to face dramatic changes, both physically and psychologically for adolescence.[9] As a result, the adolescence tends to be more willing to spend more time with the peer groups than with the parents who are considered to be watching over them more. Communication among the peer groups also experienced a number of changes. For example, they will prefer to talk about school and their dreams with their parents, but they will feel more comfortable talking about sex issues and interpersonal relationships with the opposite sex with their peer groups.

Based on some understandings above can be concluded that peer group is a social group in which there are process of transmitting values, belief systems, cultural attitudes, or behaviors so that the behavior of these groups will affect the behavior and values of individuals into its members, and the individual will form a new pattern of behavior and values that in turn can replace the values and patterns of behavior learned at home.

According to Templeton Fondation (1999), the word "character" comes from the Greek word "character" which means a constellation of strengths and weaknesses that form and express one's identity.[10] So, assessing someone's character means detecting the dominan thoughts and actions of someone. Meanwhile according to the Character Education group, the character is considered a morally neutral term.[11] The character describes the nature of the person who shows his moral qualities. Thus, the character of the person confirms his moral quality.

According to Benawa SPIRIT which manifested by (1) respect; (5) innovation; and (6) team-work characters are the idealized characters, which have to grow and develop in a person, who has personal toughness.[12]

Further Benawa described that the SPIRIT characters are the characters which can be measured by indicators, such as (1) the attitudes and actions that always want to work hard in fulfilling his dream or in achieving his success in his life; (2) the attitudes and actions that are diligent, not easy to give up in conquering any difficulties and remain enthusiastic, earnest, persistent, active, work hard, in carrying out and completing the duty to get the best achievement; (3) the attitudes and actions that can be relied upon, that represent an intact personality (integer), do not have experience friction between their 'head', 'heart' and 'hands'; (4) the attitudes and actions that always try to respect others as the realization of his respect; (5) the attitudes and actions that show innovative attitudes and actions that appear from his desire to do things that are creative, his desire to be able to find new things, his courage to face challenges, and his persistence to try the new things, his courage to take the initiative by using all his power in creating new things in order to help others fulfill their life needs; (6) the attitudes and actions that can work together in groups for the best results.[13] striving to excellence; (2) perseverance; (3) integrity; (4)

\section{MeThodology}

This research used quantitative method. The data obtained by with survey, and then processed by using path analysis to obtain information about (1) how much the effect of social media variable score (X1) has on the formation of the SPIRIT characters (X3) and (2) the effect of Peer Group variable score (X2) on the formation of the SPIRIT characters (X3).

The target population in this research was the students at Bina Nusantara University, Jakarta in the 3rd semester. The affordable population was 150 students at Bina Nusantara University in Jakarta. They became the sample frame. The number of samples taken for this research were 122 students, according to Slovin's formula[14], where:

$$
\mathrm{n}=\mathrm{N} /\left(1+\mathrm{Ne}^{\wedge} 2\right) \text {. }
$$

Information:

$\mathrm{n}=$ Number of samples

$\mathrm{N}=$ total population

e $=$ Error tolerance (for education generally $=$ $0,05)$

$$
\begin{aligned}
\text { So, } \mathrm{n}= & 300 /(1+150 \times 0,05 \times 0,05)=150 / 1,23= \\
& 121,9512=122
\end{aligned}
$$

As Kadir said to test the validity, we used Pearson Product Moment Correlation techniques.[15] While to test the reliability we used Cronbach Alpha formula. For analysing techniques, we used path analysis.

\section{RESUlTS AND FINDINGS}

Based on the data that have been processed, the result of model structural equation as follow:

$$
X_{3}=0,150 X_{1}+0,178 X_{2}+\epsilon 1 \text {. }
$$

The structure of the equation showed that the direct effect of variables $X_{1}$ and $X_{2}$ to $X_{3}$ amounted to $17.8 \%$ or a total equivalent to $32.8 \%$, where it amounted to 15.0 percent of variables $X_{1}$ and $X_{2}$ amounted to 17.8 percent, or a total equivalent to 32.8 percent. Its mean that the two variables in the model as a whole explained the variable $\mathrm{X}_{3}$ directly by 32.8 percent, the remaining amounted $67.2 \%$ is indirectly described or explained by other variables that are not described in this model.

0,672

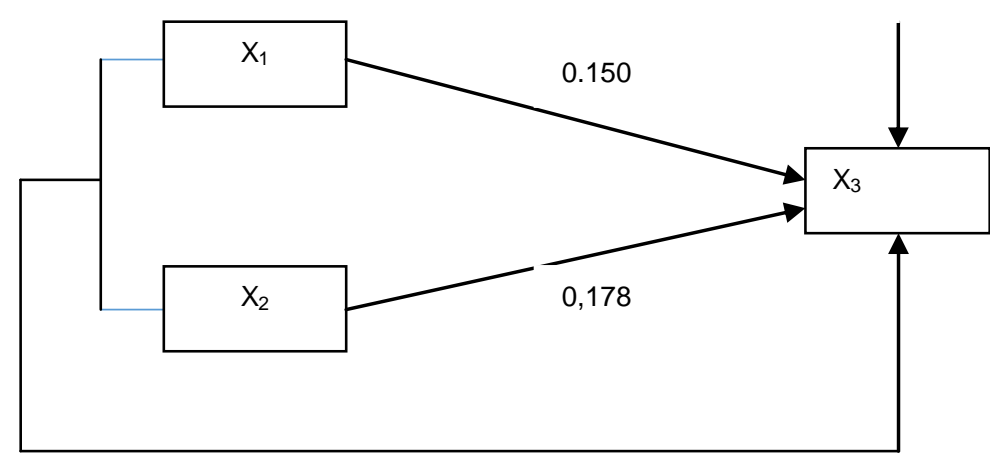

0,328

Figure of the Sturctural Model of variables $X_{1}$ and $X_{2}$ to $X_{3}$ 
Explanation:

$\mathrm{X}_{1}=$ Social Media

$\mathrm{X}_{2}=$ Peer Group

$\mathrm{X}_{3}=$ the SPIRIT Characters

After calculating of path analysis it is known that social media has a non-significant effect on the SPIRIT characters building of the students, because it only reaches 15.0 percent, while the peer group also does not have a significant effect on the SPIRIT characters building of the students, because it only reaches 17.8 percent.

Although social media as a medium of interaction between humans, whether it is between individuals and individuals, or individuals with organizations/ companies, it does not make a significant contribution. It seems that social media is not a variable that has a significant effect on the SPIRIT characters building of the students. This could be due to the lack of role of social media in inspiring the SPIRIT characters building for the students. It could also because of the SPIRIT characters are not understood yet by most of the students maybe because its were just socialized together with the celebration of 35th anniversary of Bina Nusantara University.

The same goes for the peer group. The effect of the peer group on the SPIRIT characters building is not significant. This could be due to the fact that the peer group that theoretically had an effect on the SPIRIT characters building did not significantly influence the SPIRIT characters building of the students. Is this due to the fact that students who are still in the previous semester (1-4) may not know their peer groups at Bina Nusantara University too well, or because of the SPIRIT characters are not yet well understood by them. Therefore the students who want to build the SPIRIT characters must try to understand the SPIRIT characters and choose peer groups that are conducive to the formation of the SPIRIT characters. By peer groups that are conducive to the formation of the SPIRIT characters, the students will certainly be able to feel a significant effect on the formation of the SPIRIT characters for them.

\section{CONCLUSION}

From the research about the effect of social media $\left(\mathrm{X}_{1}\right)$ and peer group $\left(\mathrm{X}_{2}\right)$ on the SPIRIT characters formation of the students $\left(\mathrm{X}_{3}\right)$ this conclusions can be conveyed as follow:

1. There is no significant positive direct effect of social media on the SPIRIT characters formation of the students.

2. There is no significant positive direct effect of peer group on the SPIRIT characters formation of the students.

Based on the conclusions above can be conveyed some suggestions as follow:

1. It is suggested for the students to enhance their understanding about the SPIRIT characters, so they can learn the inspiration about the SPIRIT characters from the usage of social media and the conducive peer groups which they choose.

2. It is suggested to the University to be more concerned to socialization about the SPIRIT characters formation, so the students in their real life can also increase the effect on the SPIRIT characters formation and more aware choosing the conducive peer group in their friendship.
3. It is also suggested that social media that used at Bina Nusantara University also more adapted to the SPIRIT characters which would be built with in each of the students in Bina Nusantara University.

\section{REFERENCES}

1 Sudijarto. (2008). Landasan dan Arah Pendidikan Nasional Kita. Jakarta: Penerbit buku Kompas.

2 Benawa, Arcadius. (2017). The Effect of Lecturer Leadership and Organizational culture on The Students' SPIRIT Character Building" Human System Interactions Article number 8005010 Pages 116-118 ISBN 978-150904688-1 DOI: 10.1109/HIS.2017.8005010.

3 Kaplan, Andreas M.; Michael Haenlein. (2010). Users of the world, unite! The challenges and opportunities of Social Media. Business Horizons 53(1): 59-68.

4 Merriam Webster. (2018). Dictionary and Thesaurus Merriam-Webster. www.merriam-webster.com. Retrieved 03-17.

5 Obar, Jonathan A.; Wildman, Steve. (2015). Social media definition and the governance challenge: An introduction to the special issue. Telecommunications policy. 39 (9): 745-750.

6 Hajirnis, Aditi. (2015). Social media networking: Parent guidance required. The Brown University Child and Adolescent Behavior Letter. 31 (12): 1-7.

7 Nielsen. (2018). State of the media: The social media report 2012 Featured Insights, Global, Media + Entertainment Retrieved 17th March.

8 Peer Group in https://sociologydictionary.org/peer-group

9 Steinberg, Laurence. (2010). Adolescence. New York: McGraw Hill. pp. 1-434. ISBN 978-0-07-353203-5.

10 Templeton Fondation. (1999). in www.crossroad.to/Quotes/spirituality/templeton.htm

11 Wing Sze MAK. 2014. Evaluation of a Moral and Character Education Group for Primary School Students. In Discovery - SS Student E-journal Vol. 3, 2014, 142-164.

12 Benawa, Arcadius. (2017). The Effect of Lecturer Leadership and Organizational culture on The Students' SPIRIT Character Building" Human System Interactions Article number 8005010 Pages 116-118 ISBN 978-150904688-1 DOI: 10.1109/HIS.2017.8005010.

13 Ibid

14 Slovin. (2006) in Steph Ellen, eHow Blog, 2017; with reference from Principles and Methods of Research; Ariola et al. (eds.).

15 Kadir. (2010). Statistika. Jakarta: Rosemata Sampurna.

\section{AUTHORS PROFILE}

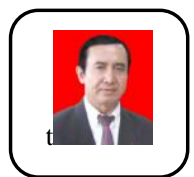

First Author Doctor in Administarion Education, write some books and scopus publications, research in humaniora, member of Serikat Dosen Indonesia,

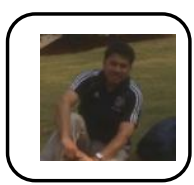

Second Author Doctor in Hystorical Research, write some publications index by scopus, research in historical issue, membership of Historical Research Doctoral. 